\section{Risk factors for psychological and physical health problems after a man-made disaster}

\author{
Prospective study
}

\author{
ANJA J. E. DIRKZWAGER, LINDA GRIEVINK, PETER G. VAN DER VELDEN \\ and $C$. JORIS YZERMANS
}

\begin{abstract}
Background There are few prospective studies on risk factors for health problems after disasters in which actual pre-disaster health data are available.
\end{abstract}

\begin{abstract}
Aims To examine whether survivors' personal characteristics, and pre-disaster psychological problems, and disasterrelated variables, are related to their postdisaster health.
\end{abstract}

Method Two studies were combined: a longitudinal survey using the electronic medical records of survivors' general practitioners (GPs), from I year before to I year after the disaster, and a survey in which questionnaires were filled in by survivors, 3 weeks and 18 months after the disaster. Data from both surveys and the electronic medical records were available for 994 survivors.

\section{Results After adjustment for demographic and disaster-related variables, pre-existing psychological problems were significantly associated with post-disaster self-reported health problems and post-disaster problems presented to the GP. This association was found for both psychological and physical post-disaster problems.}

\section{Conclusions In trying to prevent long- term health consequences after disaster, early attention to survivors with pre- existing psychological problems, and to those survivors who are forced to relocate or are exposed to many stressors during the disaster, appears appropriate.}

Declaration of interest None. Funding detailed in Acknowledgements.
Disasters can have substantial and longterm effects on the psychological and physical health of survivors (Hull et al, 2002; Morgan et al, 2003; Galea et al, 2005). Research concerning risk factors for psychological problems after disasters suggests the importance of individual characteristics (e.g. gender, ethnicity, coping), disaster-related factors (e.g. injury, relocation) and environmental factors (e.g. social support) (Brewin et al, 2000; Norris et al, 2002). Although it has been suggested that pre-disaster psychological health is an important predictor of health problems after disasters (Norris et al, 2002), recent metaanalyses showed that peri- and post-disaster variables may be more crucial predictors (Brewin, et al, 2000; Ozer et al, 2003). In disaster research, studies with actual predisaster data are rare (Reijneveld et al, 2003; Bromet et al, 2005). Pre-disaster psychological health is often measured retrospectively. Such retrospectively measured data may be influenced by recall bias and may lead to an overestimation of the relationship between disasters and psychopathology (Brewin et al, 2000; Bromet et al, 2005).

The present study focused on survivors of a major explosion at a fireworks depot in the city of Enschede in the Netherlands (13 May 2000). This explosion resulted in 22 deaths, with about 1000 injured and about 1200 local residents forced to relocate for years after their houses were destroyed. Because we could use the electronic medical records of the survivors' general practitioners (GPs), actual pre-disaster health data were available. The aim of this study was to examine to what extent survivors' personal characteristics and pre-disaster psychological problems, and disaster-related variables, were related to their post-disaster functioning and morbidity.

\section{METHOD}

\section{Participants}

After the disaster the Ministry of Health, Welfare and Sports initiated two types of study (Roorda et al, 2004). First, a longitudinal survey was started using the electronic medical records of the survivors' GPs (Yzermans et al, 2005). In The Netherlands, every person is required to register with just one GP, who must first be consulted if referral to secondary care is needed. Medical records are therefore a valuable source of information, because pre-disaster data are thus available. In the survey, $73 \%$ of the GPs in the city of Enschede participated and together they covered $89 \%$ of all survivors $(n=9329)$. All data on health problems presented to the GP from 1 year before disaster till 3.5 years after the disaster were extracted from the electronic medical records in an anonymised format. Patients were informed about their GP's participation by announcements in local newspapers and leaflets and posters in the waiting rooms, and could object to the use of their data. However, in 3 years nobody objected. The study was approved by the Dutch Data Protection Authority and the Medical Ethics Committee of The Netherlands Organization for Applied Scientific research (TNO, Zeist).

Second, a survey was launched in which self-report questionnaires were filled in by affected residents (18 years or older) at different times after the disaster (Dijkema et al, 2005; Van Kamp et al, 2005). By 3 weeks after the disaster (time 1) 1567 residents had filled in the questionnaire (estimated response rate $30 \%$ ), and 1116 of those participated 18 months after the disaster (time 2 ; response rate $71 \%$ ). All respondents signed an informed consent form before participation in the study.

For the present investigation these two studies were combined, which resulted in a group of survivors who participated in the survey by questionnaire at both times, and in the survey by record as well $(n=994)$. As directed by the Dutch Data Protection Authority, the data of the two studies were linked by an external party by means of numerical identification codes; no personal or health-related information was used for this linkage. The researchers only had access to anonymous data. These 994 survivors were compared with the adult survivors (18 years or older) who participated in the survey by record but not in the survey by questionnaire $(n=6806)$, to explore whether they differed with respect to background characteristics, pre-disaster psychological problems, and degree of forced relocation. The 994 survivors of the present study did not differ significantly from the 
other survivors with respect to gender, age, insurance type and number of persons who presented psychological problems to the GP in the year before the disaster. Compared with the other survivors, significantly more survivors participating in both the survey and the survey by record had to relocate because of the disaster $(15.9 \% \quad v .8 .4 \%$; $\chi^{2}=55.39$, d.f. $\left.=1, P<0.0001\right)$.

\section{Instruments \\ General practitioners'data}

After each contact with a patient, GPs electronically registered the presented health problems. All information on symptoms and diagnoses was classified according to the International Classification of Primary Care (ICPC; Lamberts \& Woods, 1987), which is compatible with the ICD-10 and the DSM-III-R (American Psychiatric Association, 1987; World Health Organization, 1992). Using individual ICPC codes will result in rather small numbers. Therefore, ICPC codes were combined in clusters of health problems, such as psychological, musculoskeletal, gastrointestinal or respiratory symptoms. The clusters referred to whether or not a person had presented one or more problems included in the clusters to the GP in 1 year (i.e. both the year before and the year after the disaster). Those who were registered in the general practice but did not visit the GP received a score of zero. The cluster of psychological problems consisted of ICPC codes representing stress reactions, anxiety and depressive problems/disorders. The most prevalent ICPC codes within the predisaster psychological cluster represented depressive disorder, sleeping problems, anxious feelings and depressed feelings (constituting $64 \%$ of the cluster).

In addition, data on the following demographic characteristics were available: gender, age, immigrant status (first and second generation $v$. Dutch natives), marital status (single or not) and type of health insurance. The latter was used as an indication of socio-economic status because in The Netherlands people have private health insurance when their income is above a certain level. The municipality designated a geographical area as the official disaster area, within which it was registered whether or not survivors were forced to relocate because their houses were destroyed. Such forced relocation represents additional intensity of exposure to the disaster.

\section{Self-report questionnaires}

The survivors' educational level was included in the survey (i.e. primary education; lower general secondary education; intermediate vocational education/higher general secondary education/pre-university education; vocational college/university).

At time 1, a list of 21 dichotomous items on what the survivors saw, heard, felt or smelt was presented to measure stressful experiences during the disaster. Items referred to situations, such as 'saw the explosions'; 'saw severely injured survivors'; 'heard screaming children'; 'felt the shockwaves'; 'smelt burning houses/cars'. A summary score counted the number of experiences reported. In addition, two dichotomous variables measured whether the disaster resulted in injuries of themselves and whether or not a family member or colleague died as a consequence of the disaster.

At times 1 and 2, psychological distress was measured using the Dutch adaptation of the Symptom Checklist-90-R (SCL90-R; Arrindell \& Ettema, 1986). In the present study, results for five sub-scales are presented (i.e. anxiety, depression, sleeping problems, somatisation and hostility). A 5 -point Likert scale $(1=$ not at all, $5=$ very much) was used to measure the severity of these symptoms during the preceding week. The validity and reliability of the Dutch SCL-90-R has been shown to be satisfactory. Cronbach's alpha coefficients for the sub-scales ranged from 0.88 for sleeping problems to 0.95 for depression.

At times 1 and 2, a Dutch translation of the RAND-36 Health survey was used to measure the general health status (Ware \& Sherbourne, 1992; Van der Zee \& Sanderman, 1993). In the present study, five of eight sub-scales of the RAND-36 were included: role limitations in work or daily life because of physical health problems; bodily pain; general health perceptions; social functioning; and role limitations in work or daily life because of emotional problems. Alpha coefficients for this sample ranged from 0.78 for the social functioning scale to 0.90 for bodily pain.

\section{Data analyses}

Multivariate logistic regression analyses were performed to examine risk factors for post-disaster self-reported health problems and for post-disaster health problems presented to the GP. As dependent variables dichotomised SCL-90-R and
RAND-36 sub-scales were used. For the former, the 95th percentile of a Dutch normative sample was the cut-off score, indicating a very high score (Arrindell \& Ettema, 1986). A score of 1 on the dichotomised RAND-36 scales also corresponded to a poor health outcome (i.e. a score of more than one standard deviation below the average score of a Dutch national sample; Aaronsson et al, 1998). With respect to health problems presented to the GP, the following ICPC clusters of post-disaster problems were used as dependent variables: psychological problems, injuries, and musculoskeletal, respiratory, and gastrointestinal symptoms (representing the most prevalent clusters).

The following independent variables were entered in the regression analyses: personal characteristics (i.e. gender, age, insurance type, marital status, educational level and immigrant background), disasterrelated variables (number of stressful experiences during the disaster, forced relocation, being injured or death of a significant other as a result of the disaster), and whether or not the survivor had presented psychological problems to the GP in the year before the disaster.

\section{RESULTS}

\section{Population characteristics}

The survivors had an average age of 44 years (s.d. $=14.66$, range $=17-83$ ), half of them were men $(51 \%)$, and $71 \%$ had public health insurance. The minority of the survivors were single $(28 \%)$; $17 \%$ had finished a high educational degree (university or vocational college); $17 \%(n=170)$ were of foreign origin, with 74 coming from Turkey, 23 from the rest of Europe and 73 from the rest of the world.

On average the survivors reported 10.4 stressful experiences during the disaster (s.d. $=5.41$, range $=0-20$ ). The most frequently reported experiences were: saw smoke $(89 \%)$; heard the explosion $(82 \%)$; saw the explosion $(74 \%)$; felt the shockwaves (69\%); saw damaged houses $(67 \%)$; and saw other persons in panic $(65.4 \%)$. Furthermore, $28 \%$ of the survivors saw severely injured persons and $14 \%$ saw dead persons. In addition, $6.3 \%$ got injured themselves and $5.8 \%$ lost a loved one because of the disaster.

\section{Risk factors for post-disaster self-reported health problems}

There were some consistent risk factors for the sub-scales of the SCL-90-R (Table 1): 
Table I Multivariate logistic regression analyses for the SCL-90 sub-scales at 3 weeks and 18 months after the disaster'

\begin{tabular}{|c|c|c|c|c|c|c|c|c|c|c|}
\hline \multirow[t]{2}{*}{ Variable } & \multicolumn{2}{|c|}{ Feelings of anxiety } & \multicolumn{2}{|c|}{ Feelings of depression } & \multicolumn{2}{|c|}{ Sleeping problems } & \multicolumn{2}{|c|}{ Somatisation } & \multicolumn{2}{|c|}{ Hostility } \\
\hline & OR & $95 \% \mathrm{Cl}$ & OR & $95 \% \mathrm{Cl}$ & OR & $95 \% \mathrm{Cl}$ & OR & $95 \% \mathrm{Cl}$ & OR & $95 \% \mathrm{Cl}$ \\
\hline \multicolumn{11}{|l|}{3 weeks post-disaster } \\
\hline Female gender & 1.39 & $0.96-2.03$ & 1.21 & $0.83-1.77$ & $1.53 *$ & $1.08-2.17$ & 1.00 & $0.67-1.50$ & $\mathrm{I} .53 *$ & $1.06-2.22$ \\
\hline Age (in decades) & 0.93 & $0.8 \mathrm{I}-\mathrm{I} .06$ & 0.95 & $0.82-1.08$ & 1.10 & $0.98-1.24$ & 1.08 & $0.93-1.24$ & $0.83^{* *}$ & $0.73-0.95$ \\
\hline Public health insurance & $2.99 * * *$ & $1.78-5.02$ & $1.95 * *$ & $1.20-3.18$ & $1.68 *$ & $1.08-2.59$ & $2.16 *$ & $1.26-3.72$ & $2.97 * * *$ & $1.79-4.94$ \\
\hline Immigrant status & $5.66 * * *$ & $3.67-8.73$ & $6.05^{* * *}$ & $3.92-9.33$ & $3.36 * * *$ & $2.21-5.12$ & $4.89 * * *$ & $3.13-7.64$ & $5.34 * * *$ & $3.48-8.20$ \\
\hline High educational level ${ }^{2}$ & 0.97 & $0.55-|.7|$ & 0.97 & $0.55-1.68$ & 0.83 & $0.49-1.38$ & 1.09 & $0.60-1.97$ & 0.90 & $0.52-1.58$ \\
\hline Higher degree of exposure ${ }^{3}$ & $\mathrm{I} .6 \mathrm{I}^{* * *}$ & $1.32-1.96$ & $1.50 * * *$ & $1.23-1.82$ & $1.60 * * *$ & $1.33-1.93$ & $1.57 * * *$ & $1.27-1.94$ & $1.30 * *$ & $1.08-1.56$ \\
\hline Relocation owing to disaster & 1.35 & $0.85-2.14$ & $2.45^{* * *}$ & $1.56-3.85$ & $2.0 I^{* *}$ & $1.32-3.06$ & $2.03^{* *}$ & $1.27-3.24$ & $\mathrm{I.73*}$ & I.II-2.7I \\
\hline Injury of oneself & $2.08^{*}$ & $1.07-4.07$ & 1.85 & $0.95-3.63$ & 1.20 & $0.62-2.34$ & 1.46 & $0.7 \mathrm{I}-2.99$ & $2.22^{*}$ & $1.14-4.32$ \\
\hline Pre-disaster psychological problems & $2.44 * *$ & $1.45-4.13$ & $2.08 * *$ & $1.22-3.56$ & $2.44 * * *$ & $1.5 \mathrm{I}-3.96$ & 1.73 & $0.98-3.08$ & $2.38 * *$ & $1.42-3.99$ \\
\hline \multicolumn{11}{|l|}{18 months post-disaster } \\
\hline Female gender & 1.19 & $0.75-1.88$ & 0.77 & $0.49-1.20$ & 1.45 & $0.93-2.26$ & 0.78 & $0.49-1.24$ & $1.58 *$ & $\mathrm{I} .0 \mathrm{I}-2.47$ \\
\hline Age (in decades) & 0.97 & $0.82-1.14$ & $0.82 *$ & $0.70-0.97$ & $1.25^{* *}$ & $1.07-1.46$ & 0.97 & $0.82-1.15$ & $0.83^{*}$ & $0.7 \mathrm{I}-0.98$ \\
\hline Marital status (single) & 1.09 & $0.66-1.82$ & 1.01 & $0.61-1.67$ & 0.76 & $0.46-1.26$ & 0.64 & $0.37-1.12$ & 0.67 & $0.40-1.13$ \\
\hline Public health insurance & $6.53 * * *$ & $2.72-15.68$ & $3.19 * * *$ & $1.68-6.06$ & $3.69 * * *$ & I.87-7.28 & $7.72 * * *$ & $3.01-19.82$ & $2.54 * *$ & $1.34-4.79$ \\
\hline Immigrant status & $7.24^{* * *}$ & $4.45-11.77$ & $8.93 * * *$ & $5.49-14.53$ & $4.75^{* * *}$ & $2.91-7.76$ & $7.28 * * *$ & $4.44-11.95$ & $8.05^{* * *}$ & $5.02-12.90$ \\
\hline High educational level $^{2}$ & 1.10 & $0.54-2.23$ & 1.14 & $0.59-2.21$ & 1.30 & $0.68-2.50$ & 0.59 & $0.25-I .4 I$ & 0.87 & $0.43-1.74$ \\
\hline Higher degree of exposure ${ }^{3}$ & $1.57^{* * *}$ & $1.24-2.00$ & $1.32 *$ & $1.06-1.65$ & $1.67 * * *$ & $1.32-2.12$ & 1.26 & $1.00-1.58$ & $\mathrm{I} .34^{* * *}$ & $1.07-1.66$ \\
\hline Relocation owing to disaster & 1.10 & $0.63-1.89$ & 0.88 & $0.50-1.55$ & 1.07 & $0.63-1.83$ & 1.01 & $0.58-1.78$ & 1.19 & $0.70-2.01$ \\
\hline Injury of oneself & 1.26 & $0.53-3.01$ & 1.78 & $0.77-4.13$ & 1.64 & $0.75-3.57$ & I.7I & $0.73-3.99$ & 2.03 & $0.94-4.40$ \\
\hline Death of significant other & 1.49 & $0.65-3.44$ & 1.00 & $0.42-2.42$ & 1.42 & $0.63-3.20$ & 1.08 & $0.43-2.70$ & 1.03 & $0.43-2.46$ \\
\hline
\end{tabular}

I. A score of $I$ on the dependent variable represents very high (i.e. a score in the 95th percentile of a Dutch normative sample).

2. High educational level corresponds to vocational college or a university degree v. a lower degree.

3. For the degree of exposure the unit of change was set at one standard deviation (rounded to whole numbers; this was 5). Thus, the OR of the degree of exposure was computed by an increase of 5 units.

$* P<0.05 ; * * P<0.01$; ***P<0.001.

3 weeks post-disaster, public health insurance, immigrant status and having encountered more stressful experiences during the disaster were significantly associated with high scores on all sub-scales. Except for the anxiety sub-scale, survivors who had to relocate reported more problems on the other scales. After adjusting for demographic characteristics and disaster-related variables, having presented psychological problems to the GP before the disaster was significantly associated with almost all sub-scales at 3 weeks after the disaster.

Eighteen months after the disaster, survivors with public health insurance or an immigrant background, and those experiencing more stressful situations during the disaster, still had high scores on all SCL-90-R sub-scales. Pre-disaster psychological problems were still significantly associated with feelings of depression, sleeping difficulties, somatisation and hostility.
The analyses for the RAND-36 subscales showed that, at 3 weeks postdisaster, being an immigrant and having encountered more stressful experiences during the disaster were significantly related to more problems on all sub-scales (Table 2). Survivors with public health insurance reported a worse general health, more bodily pain and more limitations because of emotional problems compared with survivors with private health insurance. Predisaster psychological problems made a significant contribution to all sub-scales, except for the sub-scale relating to role limitation because of emotional problems.

Immigrants and survivors who encountered more stressful experiences during the disaster still reported significantly more problems on all RAND-36 sub-scales 18 months after the disaster. Pre-disaster psychological problems and public health insurance were significantly associated with more problems on all but one sub-scale (i.e. general health and limitations because of physical problems respectively). Survivors who were forced to relocate reported a worse health on all sub-scales, except on the physical limitation sub-scale.

\section{Risk factors for post-disaster health problems presented to the GP}

Having experienced more stressful situations during the disaster, forced relocation and being injured during the disaster were significantly associated with post-disaster psychological problems (Table 3). In addition, women, people of older age and immigrants were more likely to present post-disaster psychological problems to their GP. Furthermore, pre-disaster psychological problems were significantly associated with post-disaster psychological problems. 
Table 2 Multivariate logistic regression analyses for the RAND-36 scales 3 weeks and 18 months after the disaster'

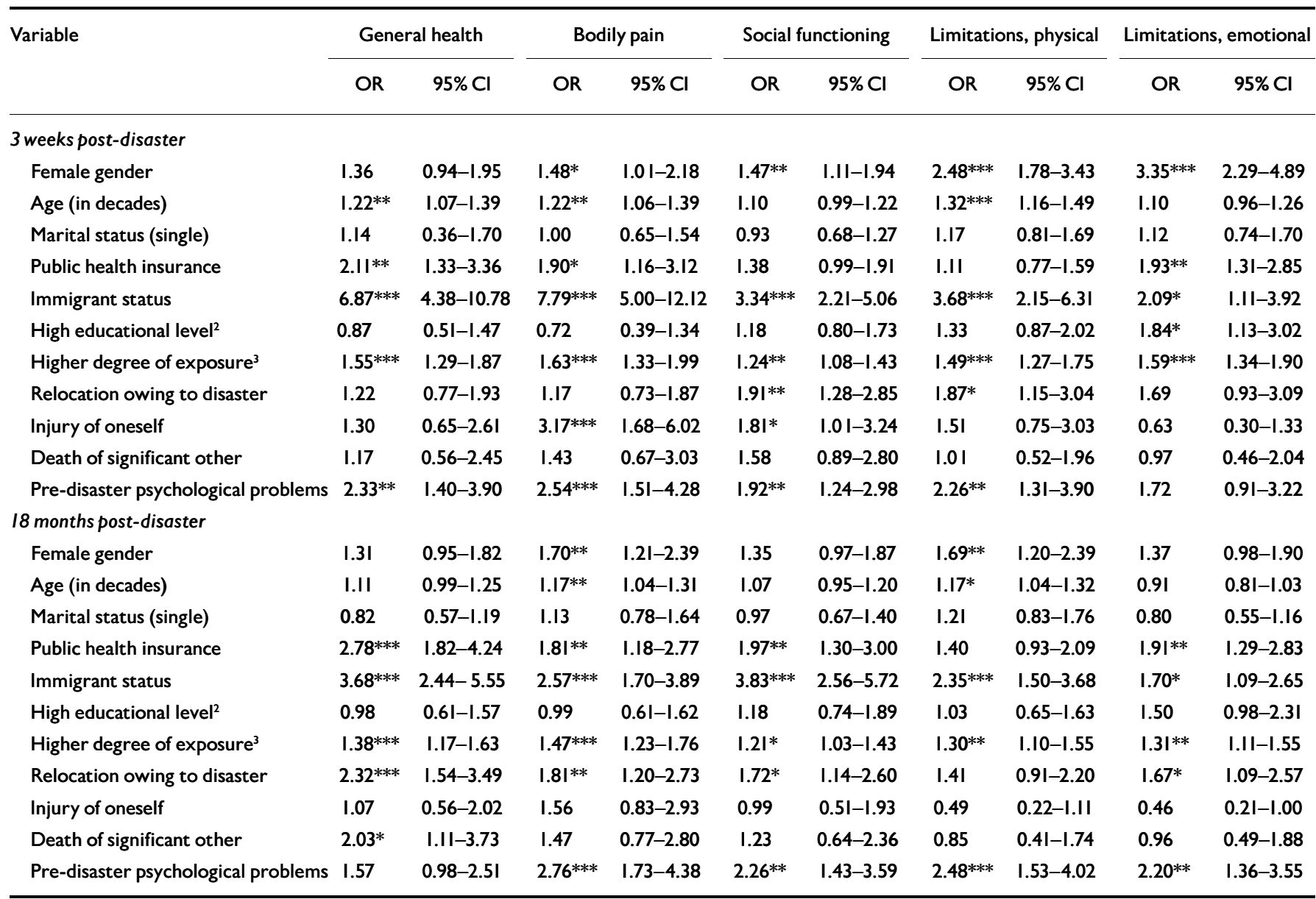

I. A score of I on the dependent variable represents a poor health outcome; i.e. a score of more than I standard deviation below the average score of a Dutch national sample.

2. High educational level corresponds to vocational college or a university degree $v$. a lower degree.

3. For the degree of exposure the unit of change was set at one standard deviation (rounded to whole numbers; this was 5). Thus, the OR of the degree of exposure was computed by an increase of 5 units.

$* \mathrm{P}<0.05 ; * * \mathrm{P}<0.01 ; * * * \mathrm{P}<0.001$

Table 3 Multivariate logistic regression analyses for health problems presented to the general practitioner during the first year after the disaster

\begin{tabular}{|c|c|c|c|c|c|c|c|c|c|c|}
\hline \multirow[t]{2}{*}{ Variable } & \multicolumn{2}{|c|}{ Psychological } & \multicolumn{2}{|c|}{ Musculoskeletal } & \multicolumn{2}{|c|}{ Gastrointestinal } & \multicolumn{2}{|c|}{ Respiratory } & \multicolumn{2}{|c|}{ Injuries } \\
\hline & OR & $95 \% \mathrm{Cl}$ & OR & $95 \% \mathrm{Cl}$ & OR & $95 \% \mathrm{Cl}$ & OR & $95 \% \mathrm{Cl}$ & OR & $95 \% \mathrm{Cl}$ \\
\hline Female gender & $1.82 * * *$ & $1.37-2.42$ & $1.47^{* *}$ & $1.11-1.95$ & 1.14 & $0.8 \mathrm{I}-\mathrm{I} .62$ & 1.15 & $0.82-1.62$ & 0.99 & $0.69-1.42$ \\
\hline Age (in decades) & $1.15^{* *}$ & $1.04-1.27$ & 1.08 & $0.98-1.19$ & 1.00 & $0.89-1.13$ & 1.01 & $0.89-1.13$ & 0.95 & $0.84-1.08$ \\
\hline Marital status (single) & 1.16 & $0.85-1.60$ & 1.35 & $0.99-1.84$ & $0.64^{*}$ & $0.42-0.97$ & 1.19 & $0.8 \mathrm{I}-\mathrm{I} .72$ & 1.25 & $0.85-1.86$ \\
\hline Public health insurance & 1.23 & $0.88-|.7|$ & 1.39 & $0.99-1.94$ & $1.6 I^{*}$ & $1.05-2.49$ & 1.35 & $0.89-2.04$ & 1.27 & $0.82-1.95$ \\
\hline Immigrant status & $2.03 * * *$ & $1.37-3.00$ & $\mathrm{I} .47^{*}$ & $1.0 \mathrm{I}-2.16$ & $2.49 * * *$ & $1.62-3.84$ & 1.00 & $0.62-1.6 \mathrm{I}$ & 1.39 & $0.87-2.21$ \\
\hline High educational level' & 1.28 & $0.87-1.90$ & $0.48^{* *}$ & $0.32-0.74$ & 0.81 & $0.47-1.38$ & 0.71 & $0.42-1.19$ & 0.71 & $0.41-1.22$ \\
\hline Higher degree of exposure ${ }^{2}$ & $1.25^{* *}$ & $\mathrm{I} .08-\mathrm{I} .44$ & 1.12 & $0.97-1.29$ & 0.92 & $0.78-1.09$ & 1.01 & $0.85-1.20$ & $\mathrm{I} .27^{*}$ & $1.06-1.52$ \\
\hline Relocation owing to disaster & $1.83^{* *}$ & $1.24-2.70$ & 0.91 & $0.62-1.34$ & 0.78 & $0.49-1.27$ & 0.93 & $0.78-|.5|$ & 0.87 & $0.54-1.42$ \\
\hline Injury of oneself & $2.27 * *$ & $1.26-4.11$ & 1.62 & $0.93-2.82$ & $2.46 * *$ & $1.33-4.53$ & 1.74 & $0.93-3.24$ & $6.95^{* * *}$ & $3.91-12.37$ \\
\hline Death of significant other & 1.78 & $0.99-3.18$ & 0.97 & $0.54-1.75$ & 0.71 & $0.32-1.57$ & 1.54 & $0.81-2.92$ & 1.28 & $0.64-2.54$ \\
\hline Pre-disaster psychological problems & $3.37 * * *$ & $2.14-5.31$ & $2.21 * * *$ & $1.44-3.37$ & I.72* & $1.06-2.80$ & 1.20 & $0.72-1.99$ & 1.31 & $0.77-2.21$ \\
\hline
\end{tabular}

I. High educational level corresponds to vocational college or a university degree $v$. a lower degree.

2. For the degree of exposure, the unit of change was set at one standard deviation (rounded to whole numbers, this was 5). Thus, the OR of the degree of exposure was computed by an increase of 5 units.

$* P<0.05$; $* * P<0.01$; $* * * P<0.001$. 
Immigrants more often presented postdisaster musculoskeletal and gastrointestinal problems to the GP when compared with natives. Having presented pre-disaster psychological problems was significantly associated with both musculoskeletal and gastrointestinal problems after the disaster.

Only disaster-related variables were significantly associated with injuries presented to the GP in the year after the disaster, indicating that the increase in injuries might be directly related to the disaster.

\section{DISCUSSION}

\section{Main findings}

In disaster research, information on the health status of survivors before the disaster is hardly ever available. The present study fills this gap by examining the independent effect of survivors' pre-disaster psychological problems, as presented to their GP during the year before a man-made disaster, on their post-disaster functioning.

After adjusting for demographic and disaster-related variables, pre-disaster psychological problems were significantly associated with worse outcomes on almost all post-disaster self-reported health problems (as measured with the SCL-90-R and RAND-36). This association was observed for post-disaster psychological as well as physical problems. In addition, this relationship was present both shortly after the disaster - at that time reflecting normal stress reactions to an abnormal situation and 18 months after the disaster. Preexisting psychological problems were also a significant risk factor for psychological, musculoskeletal and gastrointestinal problems as presented to the GP during the first year after the disaster.

These results on the association between pre-existing psychological problems and post-disaster functioning are consistent with the few prospective studies on natural disasters, which found relationships between pre- and post-disaster anxiety among children (La Greca et al, 1998; Asarnow et al, 1999), and between pre- and post-disaster depressive problems among adults (Bravo et al, 1990; Canino et al, 1990; Phifer, 1990; Nolen-Hoeksma \& Morrow, 1991; Escobar et al, 1992; Ginexi et al, 2000; Knight et al, 2000). All in all, these more rigorously designed studies seem to confirm the results of studies with only post-disaster data.

A recent prospective study on the psychological aftermath of an air show disaster demonstrated that pre-disaster mental health and perceived post-disaster threat were the strongest risk factors for postdisaster post-traumatic stress and somatisation (Bromet et al, 2005), thus also demonstrating a relationship between pre-disaster psychological problems and post-disaster physical symptoms. This is consistent with the results of the present study, which showed that pre-existing psychological problems were related to post-disaster physical symptoms, such as musculoskeletal and gastrointestinal problems, somatisation and pain. The present study adds that this association was observed for both self-reported and GP-registered physical disorders. Further research is necessary to increase our knowledge of the nature of the association between psychological problems and physical health in the context of disasters.

Besides pre-existing psychological problems, other factors are also related to post-disaster health difficulties. Both the degree of exposure to the disaster and some specific types of exposure, such as financial loss, forced relocation and injuries to oneself or family members because of the disaster, have been suggested as risk factors for post-disaster symptoms (Riad \& Norris, 1996; Norris et al, 2002). In this study, the negative effect of the degree of exposure and relocation was confirmed, whereas no clear effects of injuries of oneself or the death of a significant other were observed. The latter result may be related to the low prevalence of injuries and of death of a loved one. Relocated survivors lived in the hardest hit area and lost their homes and all personal belongings. Furthermore, because they were moved away, they may have experienced a decrease in available social support.

Immigrant background was also an important risk factor for post-disaster medical troubles. Most previous studies that included immigrant status/ethnicity were of American samples and showed that adults from minority ethnic groups more often fared worse (Norris et al, 2002). Differences in exposure to trauma, differences in coping styles and perceptions of trauma, and an already disadvantageous socio-economic situation may explain the vulnerability to health problems among immigrants (Perilla et al, 2002; Galea et al, 2004).

\section{Limitations and strengths}

A limitation of the present study is the lack of data from a control group of unexposed persons. Therefore, it remains difficult to determine whether or not the post-disaster (mental) health problems occurred after the disaster or reflect a continuation of pre-existing problems. In the survey based upon GP registrations, both pre-disaster data and data from a control group were available (Yzermans et al, 2005). In that study, an increase in post-disaster psychological and gastrointestinal problems was found among survivors, compared with both their pre-disaster rate and the control group. For the present study, the data from the survey of records were combined with the surveys based on questionnaires to examine both self-reported and GP-registered problems. This still resulted in a rather solid study design.

A second concern is the representativeness of the study sample. Although the present study addresses a sample of considerable size, this represents a relatively small group out of all survivors involved in the disaster, namely those who participated in the questionnaire surveys at both times and in the records survey as well. It is possible that selection has occurred, which may limit the generalisability of the results. A comparison of the respondents of the present study with survivors participating only in the survey of records (this group represented $89 \%$ of all survivors) showed one significant difference, suggesting that severely affected survivors (i.e. those who had to relocate) may have been slightly over-represented in the present study.

Another remark is the fact that no structured clinical interviews, which are generally considered the gold standard, were used to assess mental and/or physical health problems. Instead, self-reports and GP-diagnosed problems were used. The first survey was organised within 3 weeks of the disaster; in such a short time span, interviews were not possible. Finally, during the first wave of the survey, selfreported health and potential predictors (e.g. disaster exposure) were assessed cross-sectionally. Therefore, these cannot be seen as real predictors but only as factors associated with self-reported health troubles 3 weeks after the disaster.

The major strength of this study was the availability of actual pre-disaster data on psychological problems. Having such data is rare. Most previous studies used retrospective information about health status before the disaster, which may be influenced by recall bias (Brewin et al, 2000; Bromet et al, 2005). Another strength was 
the fact that information on post-disaster health status was obtained from two different kinds of sources: self-report measures and GP registrations. Although the information from these sources is different, both sources showed similar relationships, which strengthen the conclusions that can be drawn from this study. Finally, the study examined both psychological and physical health consequences. Until now, relatively little has been known about specific physical health consequences after disasters.

\section{Implications}

The main implication of the present study for clinicians is that survivors who have experienced psychological difficulties before the disaster are at increased risk of health troubles afterwards. Clinicians should, therefore, be extra alert for poor health outcomes among this high-risk group, and should be alert to the fact that survivors can present both psychological and physical problems. Besides, in order to try to prevent adverse long-term health consequences, early attention and interventions should not only be aimed at high-risk persons with pre-existing psychological problems, but also at survivors who are forced to relocate after a disaster or who are exposed to many stressful situations during the disaster. However, further research is needed to determine which early interventions are effective in preventing or decreasing chronic health consequences after disasters (Gray et al, 2004).

\section{ACKNOWLEDGEMENTS}

We thank the participating general practitioners. This study was funded by the Ministry of Health, Welfare and Sports in the Netherlands.

\section{REFERENCES}

Aaronson, N. K., Muller, M., Cohen, P. D., et al (1998) Translation, validation, and norming of the Dutch language version of the SF-36 Health Survey in community and chronic disease populations. Journal of Clinical Epidemiology, 5I, I055-1068.

American Psychiatric Association (1987) Diagnostic and Statistical Manual of Mental Disorders (3rd edn, revised) (DSM-III-R). Washington, DC: APA.

Arrindell, W. A. \& Ettema, J. H. M. (1986) SCL-90 Handleiding [SCL-90 Manual]. Lisse, The Netherlands: Swets \& Zeitlinger.

Asarnow, J., Glynn, S., Pynoos, R. S., et al (1999) When the earth stops shaking: earthquake sequelae among children diagnosed for pre-earthquake psychopathology. Journal of the American Academy of Child and Adolescent Psychiatry, 38, 1016-1023.

Bravo, M., Rubio-Stipec, M., Canino, G. J., et al (1990) The psychological sequelae of disaster stress

ANJA J. E. DIRKZWAGER, PhD, Netherlands Institute for Health Services Research, Utrecht; LINDA GRIEVINK, PhD, National Institute for Public Health and the Environment, Bilthoven; PETER G. VAN DER VELDEN, PhD, Institute for Psychotrauma, Zaltbommel; C. JORIS YZERMANS, PhD, Netherlands Institute for Health Services Research, Utrecht, The Netherlands

Correspondence: Dr A. J. E. Dirkzwager, NIVEL, P.O. Box 1568, 3500 BN Utrecht, The Netherlands. Tel.: +31 30 272978I; fax: +31 30 2729729; email: a.dirkzwager@nivel.nl

(First received 4 October 2005, final revision 26 January 2006, accepted 3 April 2006)

prospectively and retrospectively evaluated. American journal of Community Psychology, 18, 661-680.

Brewin, C. R., Andrews, B. \& Valentine, J. D. (2000) Meta-analysis of risk factors for posttraumatic stress disorder in trauma-exposed adults. Journal of Consulting and Clinical Psychology, 68, 748-766.

Bromet, E. J., Havenaar, J. M., Gluzman, S. F., et al (2005) Psychological aftermath of the Lviv air show disaster: a prospective controlled study. Acta Psychiatrica Scandinavica, II2, 194-200.

Canino, G., Bravo, M., Rubio-Stipec, M., et al (1990) The impact of disaster on mental health: prospective and retrospective analyses. International journal of Mental Health, 19, 51-69.

Dijkema, M., Grievink, L., Stellato, R., et al (2005) Determinants of response in a longitudinal health study following the firework disaster in Enschede, the Netherlands. European Journal of Epidemiology, 20, 839-847.

Escobar, J. I., Canino, G., Rubio-Stipec, M., et al (1992) Somatic symptoms after a natural disaster: a prospective study. American Journal of Psychiatry, 149 965-967.

Galea, S., Vlahov, D., Tracy, M., et al (2004) Hispanic ethnicity and post-traumatic stress disorder after a disaster: evidence from a general population survey after September II, 200I. Annals of Epidemiology, 14, 520-531.

Galea, S., Nandi, A. \& Vlahov, D. (2005) The epidemiology of posttraumatic stress disorder after disasters. Epidemiologic Reviews, 27, 78-91.

Ginexi, E. M., Weish, K., Simmens, S. J., et al (2000) Natural disaster and depression: a prospective investigation of reactions to the 1993 Midwest floods. American Journal of Community Psychology, 28, 495-518.

Gray, M. J., Litz, B. T. \& Maguen, S. (2004) Acute psychological impact of disaster and large-scale trauma: limitations of traditional interventions and future practice recommendations. Prehospital and Disaster Medicine, 19, 64-72.

Hull, A. M., Alexander, D. A. \& Klein, S. (2002) Survivors of the Piper Alpha oil platform disaster: longterm follow-up study. British Journal of Psychiatry, $\mathbf{1 8 I}$ 433-438

Knight, B. G., Gatz, M., Heller, K., et al (2000) Age and emotional response to the Northridge earthquake: a longitudinal analysis. Psychology and Aging, 15, 627-634

La Greca, A. M., Silverman, W. K. \& Wasserstein, S. B. (1998) Children's predisaster functioning as a predictor of posttraumatic stress following Hurricane Andrew. Journal of Consulting and Clinical Psychology, 66 883-892.

Lamberts, H. \& Woods, M. (1987) International Classification of Primary Care. Oxford: Oxford University Press.

Morgan, L., Scourfield, J., Williams, D., et al (2003) The Aberfan disaster: 33-year follow-up of survivors. British Journal of Psychiatry, 182, 532-536.
Nolen-Hoeksma, S. \& Morrow, J. (1991) A prospective study of depression and posttraumatic stress symptoms after a natural disaster: the 1989 Loma Prieta earthquake. Journal of Personality and Social Psychology, 61, 115-121.

Norris, F. H., Friedman, M. J., Watson, P. J., et al (2002) 60,000 disaster victims speak. Part I: an empirical review of the empirical literature, 1981-200I. Psychiatry, 65, 207-239.

Ozer, E. J., Best, S. R., Lipsey, T. L., et al (2003) Predictors of posttraumatic stress disorder and symptoms in adults: a meta-analysis. Psychological Bulletin, 129, 52-73.

Perilla, J. L., Norris, F. H. \& Lavizzo, E. A. (2002) Ethnicity, culture, and disaster response: identifying and explaining ethnic differences in PTSD six months after hurricane Andrew. Journal of Social and Clinical Psychology, 21, 20-45.

Phifer, J. F. (1990) Psychological distress and somatic symptoms after natural disaster: differential vulnerability among older adults. Psychology and Aging, 5, 412-420.

Reijneveld, S. A., Crone, M. R., Verhulst F. C., et al (2003) The effect of a severe disaster on the mental health of adolescents: a controlled study. Lancet, 362 691-696.

Riad, J. \& Norris, F. (1996) The influence of relocation on the environmental, social, and psychological stress experienced by disaster victims. Environment and Behavior, 28, 63-182.

Roorda, J., van Stiphout, W. A. \& HuijsmanRubingh, R. (2004) Post-disaster health effects: strategies for investigation and data collection. Experiences from the Enschede firework disaster. Journal of Epidemiology and Community Health, $\mathbf{5 8}$ 982-987.

Van der Zee, K. I. \& Sanderman, R. (1993) Het Meten van de Algemene Gezondheidstoestand met de RAND-36. Een Handleiding [Measuring general health with the RAND-36: a manual]. Groningen, The Netherlands: Noordelijk Centrum voor Gezondheidsvraagstukken.

Van Kamp, I., van der Velden, P. G., Stellato, R., et al (2005) Physical and mental health shortly after a disaster: first results from the Enschede firework disaster study. European Journal of Public Health. Advance access published on September 12, 2005; doi:I0.1093/ eurpub/ckil88.

Ware, J. E. \& Sherbourne, C. D. (1992) The MOS 36-item short-form Health Survey (SF-36). I. Conceptual framework and item selection. Medical Care, 30, 473-48I.

World Health Organization (1992) ICD-10: International Statistical Classificaiton of Disorders and Related Health Problems. Vol. I. Geneva: WHO.

Yzermans, C. J., Donker, G. A., Kerssens, J. J., et al (2005) Health problems of victims before and after disaster: a longitudinal study in general practice. International Journal of Epidemiology, 34, 810-819. 